\title{
The Effect of Central Business District on House Prices in Chengdu Metropolitan Area: A Hedonic Approach
}

\author{
Gaolu Zou \\ Chengdu Economic and Development Institute of Conventions and Exhibitions, Chengdu University, Chengdu 610106, \\ Sichuan Province, China
}

\begin{abstract}
This paper aims to analyse the effects of the CBD and several selected housing features on house prices in Chengdu. Sampling is focused on ordinary old housing units. Data were collected from metropolitan Chengdu, China. Utilizing log-linear hedonic techniques, the study suggests a small negative price gradient from the CBD and a marginal and nonlinear effect of housing age and underground railway locations on house prices. Therefore, the study supports the classic inference for spatial house prices. Additionally, we suggest higher property tax rates for large-floor space units.
\end{abstract}

Keywords-central business district; housing feature; price, hedonic; log-linear; marginal effect.

\section{INTRODUCTION}

Chengdu metropolis displays a spatially concentric pattern. Classic urban housing market modeling starts from a monocentric city with an only business or employment center (the Central Business District known as CBD), e.g. $[1,2]$. House prices vary inversely with distance or travel time to the CBD, holding other amenities constant. This is because the housing spatial equilibrium requires a negative price gradient. However, empirical evidence for the negative price gradient is inconsistent[3]. For a long period, the CBD did not affect house prices. However, house values now decline by more than $8 \%$ per mile (from the CBD)[4].

The CBD in Chengdu is situated in Yan Shi Kou nexus. Starting from CBD outwards are four ring expressways, i.e., Ring Road No. 1, Ring Road No. 2, Ring Road No. 3 and Around-the-city Expressway. Renming Nan Lu Road and Shu Du Da Dao Avenue are two main radial avenues starting from CBD outwards. Thus, nonlinear and concave urban property prices may exist in Chengdu metropolitan area[5, 6]. House prices have a tendency to change marginally with various features such as the distance and age[7].

Chengdu has since 2008 conducted large-scale development activities on underground railways. The dual effects of urban transit tracks on real estate prices are suggested[8-10]. Elasticity of private house price relative to walking distance is $-0.02[11]$. Railway stations[12], light rails[13], underground stations[5] increased either land or house values. However, negative externalities such as noise and congestion reduced house prices[ 8,14$]$.

This paper mainly aims to examine the nonlinear effects of the CBD and several selected housing featureson house prices in metropolitan Chengdu. We introduced a hedonic technique and thus estimated implicit house prices. We expect that the paper would contribute to the house price gradient from the CBD, property valuation and property tax policy.

\section{METHODOLOGY}

Housing properties are composed of various features[14, 15]. Hedonic methods could discover the prices of these housing features[16]. Hedonic prices are often called implicit prices because they are not explicitly 'viewed' or listed on board. [17] suggested the alternative functional forms of hedonic models. Past studies on real estate markets widely use hedonic techniques, e.g. [14, 18-28].

One commonly used hedonic technique is the log-linear equation[29-31]. Right inferences could be reached using the log-linear form[32]. It is formulated as

$$
\text { In PRICE }=\alpha+\sum_{i=1}^{m} \beta_{i} \ln X_{i}+\sum_{j=1}^{n} c_{j} D_{j}+\varepsilon
$$

Where PRICE is the house price. $X_{\mathrm{i}}$ represents the $i^{\text {th }}$ feature of $m$ housing features. $D_{\mathrm{j}}$ represents the $j^{\text {th }}$ feature of $n$ housing features. $D$ stands for dummy variable, e.g. CBD location and lake view. Ln denotes the natural logarithm. $\varepsilon$ is an error term. $\beta_{\mathrm{i}}$ is constant elasticity given continual variable $X_{\mathrm{i}}$, or implicit price $P_{\mathrm{i}}=X_{i}^{\beta_{i}}$ given integer variable $X_{\mathrm{i}}$. Existence of $D_{\mathrm{j}}$ implies that price change is $\left(e^{c_{j}}-1\right) \times 100 \%$ [33]. Marginal house price changes could be suggested using estimates of the coefficients[7].

\section{DATA AND VARIABLE DEFINITION}

We selected 180 ordinary-type older units in Chengdu metropolitan area. Sampling area is bounded within the Around-the-city Expressway. Suppose that eleven housing features impact house price PRICE. For each housing unit, the selected 11 features include floor space $A R E A$, number of bedrooms BEDROOM, number of halls HALL, number of bathrooms BATHROOM, floor level FLOORLEVEL, house age $Y E A R$, green coverage rate GREENCOVERAGE, decoration DECORATION, distance to CBDDIST CBD, ring location RING, walking distance to nearest underground railway station UNDERGROUND. Data contain 2160 observations. Sampling spans the period from mid-January to mid-April. Table 1 statistically describes the raw data. We defined various details for house price and the 
11 features as follows.

House price is call price listed on websites[34, 35]. The call price is a supply-side price. Floor space is limited to 50 to 200 square meters. Distance to CBD is that to Yan Shi Kou (city center). The city government has planned that Yan Shi Kou is CBD, where business buildings and activities become highly concentrated. Ring location (dummy variable) includes core area within Ring Road No. $1(=1)$, ring zone 1 between Ring Road No. 1 and Ring Road No. $2(=2)$, ring zone 2 between Ring Road No. 2 and Ring Road No. 3 (=3), and ring zone 3between Ring Road
No. 3 and Around-the-city Expressway (=4).

There are two underground railway lines currently available in Chengdu. Walking distance to nearest underground railway station is divided into five zones and corresponding dummy variables: up to 400 meters (below five minutes) denoted by 1401 to 800 meters (five to ten minutes) denoted by 2801 to 1200 meters (ten to fifteen minutes) denoted by 3, 1201 to 1600 meters (fifteen to twenty minutes) denoted by 4, and above 1600 meters (above twenty minutes) denoted by 5 .

TABLE I. STATISTICAL DESCRIPTION FOR THE RAW DATA

\begin{tabular}{|c|c|c|c|c|c|c|c|}
\hline & Mean & Median & Maximum & Minimum & Standard. Deviation & Jarque-Bera & P-value \\
\hline PRICE & 97.8 & 88 & 365 & 43 & 41.1 & 1354.7 & 0.00 \\
\hline$A R E A$ (sq. meters) & 99.7 & 91.95 & 223 & 49 & 28.1 & 87.2 & 0.00 \\
\hline DECORATION & 3.1 & 4 & 4 & 1 & 1.3 & 30.1 & 0.00 \\
\hline BEDROOM & 2.5 & 2 & 5 & 1 & 0.7 & 7.3 & 0.03 \\
\hline$H A L L$ & 2.0 & 2 & 3 & 1 & 0.3 & 368.5 & 0.00 \\
\hline BATHROOM & 1.5 & 1 & 3 & 1 & 0.6 & 20.5 & 0.00 \\
\hline FLOOR LEVEL & 9.8 & 7 & 33 & 1 & 8.1 & 46.2 & 0.00 \\
\hline YEAR & 8.6 & 8 & 29 & 1 & 4.7 & 68.6 & 0.00 \\
\hline GREENCOVERAGE(\%) & 29.3 & 30 & 70 & 1.7 & 12.5 & 19.9 & 0.00 \\
\hline RING & 2.6 & 3 & 4 & 1 & 1.1 & 13.2 & 0.00 \\
\hline$D I S T \_C B D$ (meters) & 4939.3 & 5270 & 12867.8 & 201 & 2661.3 & 0.4 & 0.81 \\
\hline UNDERGROUND & 4.1 & 5 & 5 & 1 & 1.3 & 35.5 & 0.00 \\
\hline
\end{tabular}

\section{ESTIMATION AND ANALYSIS}

We took a stepwise regression strategy. Preliminary regression (Table II) suggested that five out of 11 variables were statistically insignificant. However, we found that removing $R I N G$ and $H A L L$ from the regression did not increase the values of R-squared and adjusted R-squared, but led to worsening heteroskedasticity. Thus, we could not remove more features than two from the regressions. We decided the estimated results in Table III. Fitness appears to be satisfactory, figure. 1 .

TABLE II. RESULTS OF PRELIMINARY REGRESSION.

\begin{tabular}{|c|c|c|c|}
\hline Variable & Estimate & t-statistic & P-value \\
\hline LOG(AREA) & 0.89 & 8.35 & 0.00 \\
\hline LOG(DECORATION) & 0.04 & 1.59 & 0.11 \\
\hline LOG(BEDROOM $)$ & 0.07 & 0.89 & 0.37 \\
\hline LOG(HALL) & 0.07 & 0.80 & 0.42 \\
\hline LOG(BATHROOM) & 0.06 & 1.10 & 0.27 \\
\hline LOG(FLOORLEVEL) & -0.01 & -0.84 & 0.40 \\
\hline LOG(YEAR) & -0.16 & -5.22 & 0.00 \\
\hline LOG(GREENCOVERAGE) & 0.05 & 2.79 & 0.01 \\
\hline LOG(RING) & 0.01 & 0.12 & 0.91 \\
\hline LOG(DIST_CBD $)$ & -0.09 & -2.04 & 0.04 \\
\hline LOG(UNDERGROUND) & -0.08 & -1.90 & 0.06 \\
\hline Error term & 1.31 & 2.30 & 0.02 \\
\hline
\end{tabular}

Notes: R-squared=0.72, Adjusted R-squared $=0.70$, S.E. of regression=0.19,
F-statistic=39.2. White Heteroskedasticity $(\mathrm{P}$-value $)=35.7(0.03)$.

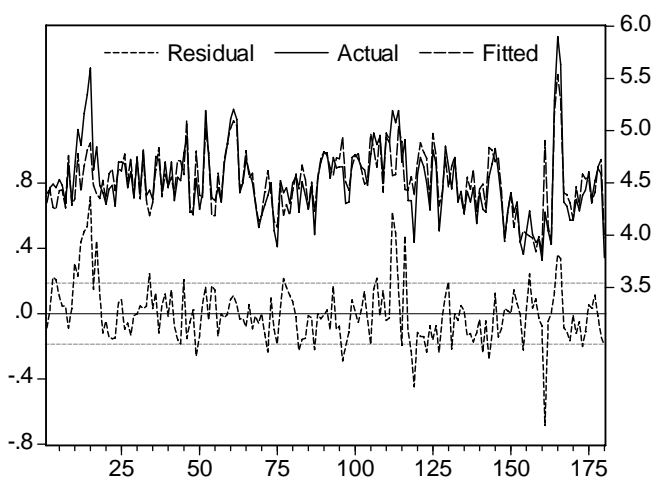

Figure 1. Actual and fitted values for house prices

Estimates are significant for AREA, DECORATION, YEAR, GREENCOVERAGE, DIST CBD, and $U N D E R G R O U N D$. Hence, given other features constant, the growth of $1 \%$ in distance from the CBD implies that the price reduces by about $0.1 \%$. However, a $1 \%$ growth in floor area implies that the house price grows by $0.92 \%$. A growth of $10 \%$ in green coverage rate may provoke a rise of $0.5 \%$ in price.

Given other features constant, for an average one-year 'new' unit, the implicit price is $1^{(-0.17)}=1$ yuan RMB/sqm. For an average 5-year unit, the implicit price is $5^{(-0.17)}=0.76$ 
yuan $\mathrm{RMB} / \mathrm{sqm}$. For an average 10-year unit, the implicit price is $10^{(-0.17)}=0.68$ yuan $\mathrm{RMB} / \mathrm{sqm}$, and so on. Hence, house prices normally decrease marginally with house ages, figure. 2 .

TABLE III. RESULTS OF STEPWISE REGRESSIONS

\begin{tabular}{llll}
\hline Variable & Estimate & t-statistic & P-value \\
\hline LOG(AREA) & 0.92 & 9.06 & 0.00 \\
LOG(DECORATION) & 0.05 & 1.68 & 0.09 \\
LOG(BEDROOM) & 0.07 & 0.94 & 0.35 \\
LOG(BATHROOM) & 0.06 & 1.06 & 0.29 \\
LOG(FLOORLEVEL) & -0.01 & -0.84 & 0.40 \\
LOG(YEAR) & -0.17 & -5.38 & 0.00 \\
LOG(GREENCOVERAGE) & 0.05 & 2.76 & 0.01 \\
LOG(DIST_CBD) & -0.09 & -3.83 & 0.00 \\
LOG(UNDERGROUND) & -0.07 & -1.85 & 0.07 \\
\multicolumn{1}{c}{ Error term } & 1.19 & 2.60 & 0.01 \\
\hline
\end{tabular}

Notes: R-squared $=0.72$, Adjusted R-squared $=0.70$, S.E. of regression $=0.19$, F-statistic $=48.2$, White Heteroskedasticity $(\mathrm{P}$-value $)=34.0(0.01)$.

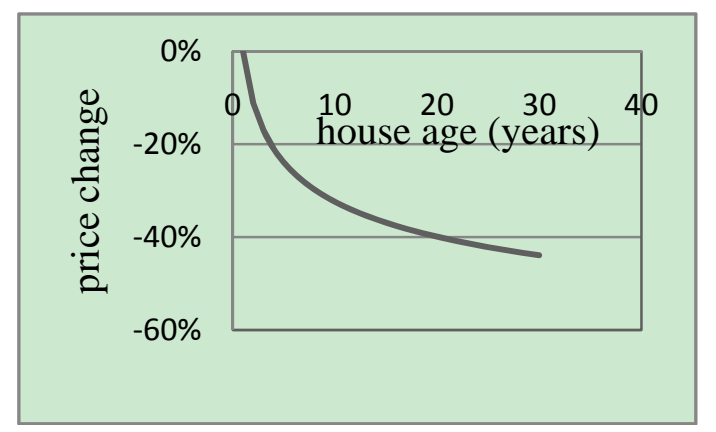

Figure 2. House prices decreased marginally with age

Given other features constant, for an average unit, the implicit price for the walking distance of 400 to 800 meters to nearest ground station, relative to the walking distance of within 400 meters, reduces by $4.7 \%\left(2^{(-0.07)}-1\right)$. The implicit price for the walking distance of 801 to 1200 meters to station reduces by $7.4 \%$. The implicit price for the walking distance of 1201 to 1600 meters to station reduces by $9.2 \%$. The implicit price for the walking distance exceeding 1600 meters to station reduces by $10.7 \%$. Thus, effects of walking distance to rail station on house prices are nonlinear and marginal, fig.3.

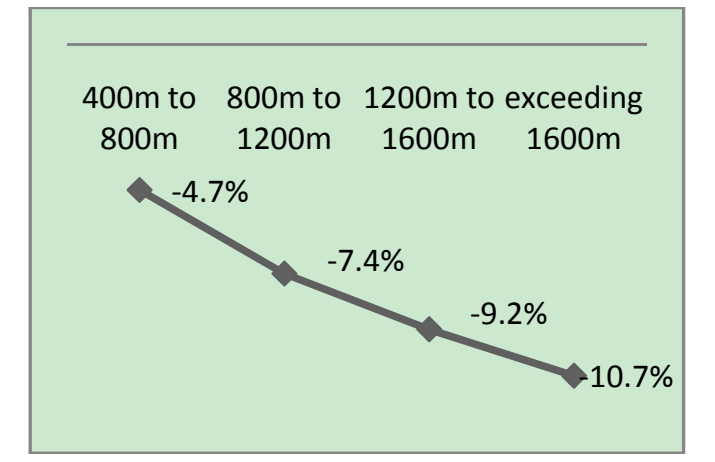

Figure 3. House prices decreased nonlinearly with walking distance to nearest underground stationgiven the price in the zone within 400 meters (=1)

\section{CONCLUSIONS}

It has been argued that house prices vary inversely with distance or travel time to the CBD. Various structural and environmental features impact housing prices. Few studies analyzed the implicit prices in Chengdu. The Chengdu metropolis is characterized by a monocentric pattern and has rapidly expanded in terms of economy, population and built area over the past decade. Two underground railway lines are in effect. Five others are in construction. We selected ordinary-type older housing units within the Around-the-city Expressway.

The paper employed a hedonic technique and conducted regressions using log-linear equations. We find that house prices decrease with distance from CBD and walking distance to the nearest underground station. The finding supports a negative price gradient from the CBD. In addition, larger floor space, good decoration and higher green coverage increase but age reduces house prices.

We suggest that the government could impose higher property tax rates on units with a larger floor space than those with a smaller floor space.

\section{ACKNOWLEDGMENTS}

A Project Supported by Scientific Research Fund of SiChuan Provincial Education Department (2014-2015).

\section{REFERENCES}

[1] Alonso, W., Location and land use. Cambridge, MA.: Harvard University Press, 1964.

[2] Fujita, M., Spatial patterns of residential development. Journal of Urban Economics, 12(1), pp. 22-52, 1982.

[3] Bender, B. \& Hwang H.-S., Hedonic housing price indices and secondary employment centers. Journal of Urban Economics, 17(1), pp. 90-107, 1985.

[4] McMillen, D.P., The return of centralization to chicago: Using repeat sales to identify changes in house price distance gradients. Regional Science and Urban Economics, 33(3), pp. 287-304, 2003.

[5] Wieser, R. Hedonic prices on viennás urban residential land markets, working paper nr.: 2/2006. IFIP-working paper 2/2006: Centre of Public Finance and Infrastructure Policy, Vienna University of Technology. 2006.

[6] Colwell, P.F. \& Munneke H.J., The structure of urban land prices. Journal of Urban Economics, 41(3), pp. 321-336, 1997.

[7] DiPasquale, D. \& Wheaton W.C., Urban economics and real estate 
markets. New Jersey, Englewood Cliffs: Prentice-Hall, 1996.

[8] Simons, R.A. \& El Jaouhari A., The effect of freight railroad tracks and train activity on residential property values. Appraisal Journal, 72(3), pp. 223-233, 2004.

[9] Smith, J.J. \& Gihring T.A., Financing transit systems through value capture. American Journal of Economics and Sociology, 65(3), pp. 751-786, 2006.

[10] Kilpatrick, J.A., Throupe R.L., Carruthers J.I. \& Krause A., The impact of transit corridors on residential property values. Journal of Real Estate Research, 29(3), pp. 303-320, 2007.

[11] Mok, H.M., Chan P.P. \& Cho Y.-S., A hedonic price model for private properties in hong kong. The Journal of Real Estate Finance and Economics, 10(1), pp. 37-48, 1995.

[12] Voith, R., Changing capitalization of cbd-oriented transportation systems: Evidence from philadelphia, 1970-1988. Journal of Urban Economics, 33(3), pp. 361-376, 1993.

[13] Knaap, G., Hopkins L. \& Pant A. Does transportation planning matter? Explorations into the effects of planned transportation infrastructure on real estate sales, land values, building permits, and development sequence. Research Paper, Lincoln Institute of Land Policy. 1996.

[14] Forrest, D., Glen J. \& Ward R., The impact of a light rail system on the structure of house prices: A hedonic longitudinal study. Journal of Transport Economics and Policy, pp. 15-29, 1996.

[15] Chau, K., Wong S., Yiu C. \& Leung H., Real estate price indices in hong kong. Journal of Real Estate Literature, 13(3), pp. 337-356, 2005.

[16] Rosen, S., Hedonic prices and implicit markets: Product differentiation in pure competition. Journal of Political Economy, 82(1), pp. 34-55, 1974.

[17] Halvorsen, R., Henry O. Pollakowski. , Choice of functional form for hedonic price equations. Journal of Urban Economics, 10(1), pp. 37-49, 1981.

[18] Besner, C., A spatial autoregressive specification with a comparable sales weighting scheme. Journal of Real Estate Research, 24(2), pp. 193-211, 2002.

[19] Blackley, D.M., Follain J.R. \& Lee H., An evaluation of hedonic price indexes for thirty-four large smsas. AREUEA Journal: Journal of the American Real Estate \& Urban Economics Association, 14(2), pp. 179-205, 1986.

[20] Bourassa, S., Cantoni E. \& Hoesli M., Spatial dependence, housing submarkets, and house price prediction. Journal of Real Estate
Finance \& Economics, 35(2), pp. 143-160, 2007.

[21] Brasington, D.M., Which measures of school quality does the housing market value? Journal of Real Estate Research, 18(3), pp. 395, 1999.

[22] Butsic, V., Hanak E. \& Valletta R.G., Climate change and housing prices: Hedonic estimates for ski resorts in western north america. Land Economics, 87(1), pp. 75-91, 2011.

[23] Dale-Johnson, D. \& Phillips G.M., Housing attributes associated with capital gain. AREUEA Journal: Journal of the American Real Estate \& Urban Economics Association, 12(2), pp. 162-175, 1984.

[24] Dinan, T.M. \& Miranowski J.A., Estimating the implicit price of energy efficiency improvements in the residential housing market: A hedonic approach. Journal of Urban Economics, 25(1), pp. 52-67, 1989.

[25] Goodman, A.C., Hedonic prices, price indices and housing markets. Journal of Urban Economics, 5(4), pp. 471-484, 1978

[26] Goodman, A.C. \& Thibodeau T.G., The spatial proximity of metropolitan area housing submarkets. Real Estate Economics, 35(2), pp. 209-232, 2007.

[27] Harding, J.P., Knight J.R. \& Sirmans C.F., Estimating bargaining effects in hedonic models: Evidence from the housing market. Real Estate Economics, 31(4), pp. 601-622, 2003.

[28] Jim, C. \& Chen W.Y., Value of scenic views: Hedonic assessment of private housing in hong kong. Landscape and Urban Planning, 91(4), pp. 226-234, 2009.

[29] Case, B., Pollakowski H.O. \& Wachter S.M., On choosing among house price index methodologies. Real Estate Economics, 19(3), pp. 286-307, 1991.

[30] Gatzlaff, D.H. \& Ling D.C., Measuring changes in local house prices: An empirical investigation of alternative methodologies. Journal of Urban Economics, 35(2), pp. 221-244, 1994.

[31] Benson, E.D., Hansen J.L., Schwartz Jr A.L. \& Smersh G.T., The influence of canadian investment on u.S. Residential property values. Journal of Real Estate Research, 13(3), pp. 231-249, 1997.

[32] Kang, H.B. \& Reichert A.K., An evaluation of alternative estimation techniques and functional forms in developing statistical appraisal models. Journal of Real Estate Research, 2(1), pp. 1-29, 1996.

[33] Wooldridge, J.M., Introductory econometrics: A modern approach: South-Western Pub, 2009.

[34] Sohu. Second-hand real estate. http://cd.esf.focus.cn/shop/. 2014. Sina. Second-hand real estate. http://cd.esf.sina.com.cn/. 2014 